\title{
Influencia de la temperatura del clínker sobre su molturabilidad
}

\author{
Z. Pospisil, Prerov. Checoslovaquia \\ Zement-Kalk-Gips, núm. 1, año 32, págs. 20-23. Enero 1979
}

El objeto del trabajo experimental que Z. Pospisil describe es demostrar que la disminución del rendimiento en la molienda del clínker no se debe tanto en la influencia de la temperatura, como a la carga electrostática que se engendra durante la pulverización del clínker.

La necesidad de estudiar la cuestión se debe a que, generalmente, se muele clínker poco enfriado por ser muy limitadas las posibilidades de enfriarle en los silos.

La molturación del clínker de cemento portland requiere un considerable consumo de energía.

Para una producción anual, mundial, de 500 millones de toneladas, con un consumo específico de $35 \mathrm{~kW} / \mathrm{t}$, el consumo de energía es cercano a 18.000 millones de $\mathrm{kW} / \mathrm{h}$ que corresponde al $0,5 \%$ de la total producción mundial de electricidad.

\section{FACTORES QUE INFLUYEN SOBRE LA MOLTURABILIDAD}

\section{Porosidad}

El clínker poroso de un horno Lepol requiere $17 \%$ menos energía para su molturación que el clínker de un horno con precalentador, pero se ha encontrado que para finuras superiores a los $2.000 \mathrm{~cm}^{2} / \mathrm{g}$ el efecto es poco pronunciado.

\section{Cal y magnesia}

La cal libre tiene un efecto positivo, pues sus partículas carecen de una firme unión con el material que las rodea, y esto perturba la estructura de la masa.

Un incremento en la magnesia libre tiene un efecto negativo en la molturabilidad; por encima del $2 \%$ de $\mathrm{MgO}$ se halla en forma de periclasa que dificulta la molienda. 


\section{Silicatos}

La molturabilidad aumenta al incrementarse el contenido de $\mathrm{C}_{3} \mathrm{~S}$ y decrece al acrecentar el $\mathrm{C}_{2} \mathrm{~S}$; la tendencia a la aglomeración aumenta con $\mathrm{C}_{2} \mathrm{~S}$.

\section{Otras influencias}

En el proceso "seco" el tipo de precalentador influye algo. Las condiciones de la calcinación y el enfriamiento afectan al contenido de fase vítrea y de energía interna que, a su vez, influyen sobre la molturabilidad y resistencias mecánicas del clínker.

\section{Efecto de la temperatura}

La disminución de la eficacia de los molinos es causada por la adhesión del material motivada por las cargas electrostáticas que aparecen en la superficie de las partículas cuando se alcanzan altos valores de la superficie específica. La adherencia a los cuerpos moledores y a las paredes de los molinos se incrementan al aumentar la temperatura. Las partículas de cemento portland adsorben aire formándose una capa que las aisla entre sí; por encima de $100^{\circ} \mathrm{C}$ la película de aire se destruye y las cargas electrostáticas producen agregados compactos.

Hay que agregar la deshidratación de yeso $\mathrm{CaSO}_{4} \cdot 2 \mathrm{H}_{2} \mathrm{O}$ transformándose en hemihidrato y anhidrita con efectos perjudiciales sobre el fraguado y endurecimiento del cemento.

\section{EXPERIENCIAS REALIZADAS}

El autor describe las experiencias realizadas en dos escalas: En molino de laboratorio y en molino de una fábrica.

\section{Experiencias de laboratorio}

La finalidad es investigar la variación de molturabilidad en un intervalo de temperaturas comprendido entre 20 y $200^{\circ} \mathrm{C}$.

El factor de molturabilidad se calcula por la ecuación KVTI $=2\left(\ln 100 / Z_{0,09}\right)^{2 / 3}$. $Z_{0,09}$ es el peso, en gramos, del residuo que no pasa por el tamiz de 0,09 $\mathrm{mm}$ de luz, al cribar 100 gramos del clínker molido.

El molino utilizado fue un cilindro de $270 \mathrm{~mm}$ de longitud y $210 \mathrm{~mm}$ de diámetro interior.

El molino se situó dentro de una cúbierta aislante (fig. 1) provista de ruedas que permitían su deslizamiento longitudinal. El recinto se calentó por cuatro resistencias eléctricas separadas del cilindro por una pantalia y el aire se hizo circular mediante un ventilador. La temperatura se estabilizó con una seguridad de $\pm 1^{\circ} \mathrm{C}$; además del pirómetro se instaló un termómetro de mercurio. 
Fig. 1.- Escluema de la instalactón de laboratorio para la experimentación del efecto de la remperatura sobre la molturabilidad.

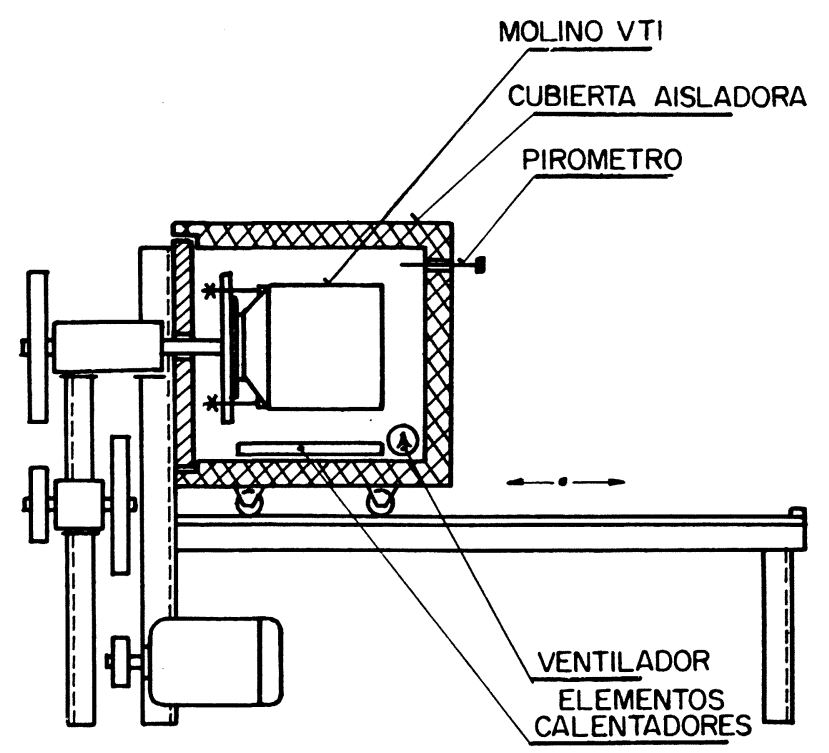

Todos los elementos de regulación se conectaron en un cuadro de distribución.

La muestra de clínker se trituró a mano, previamente y se afinó, después, en un mortero rotatorio; se operó así hasta obtener un material con granos de 2 a $3 \mathrm{~mm}$.

$0,5 \mathrm{~g}$ de este material se introdujeron en el cilindro moledor que, previamente, se había cargado con $6 \mathrm{~kg}$ de bolas de porcelana, de $35 \mathrm{~mm}$ de diámetro, y $2 \mathrm{~kg}$ de bolas de porcelana, de $15 \mathrm{~mm}$ de diámetro. El cilindro se conectó con el sistema de rotación, se adaptó la cubierta aislante y comenzó a calentarse durante 30 minutos pues se había comprobada que así todo el conjunto alcanzaba la temperatura previamente escogida para cada ensaryo.

Se inició la rotación que a las 615 revoluciones se detuvo. Se apartó la cubierta y dejó enfriar.

La muestra de clínker molida se extrajo y tamizó con el tamiz de $0,09 \mathrm{~mm}$ de luz para apreciar el residuo, cuyo valor se llevó a la ecuación que permitió obtener el índice KvTr.

\section{Material ensayado}

La molturabilidad se ensayó en clínker procedente de tres fábricas, obtenido por vía seca y que presentaba difícil molturabilidad.

Cada muestra se ensayó cinco veces a cada una de las siguientes temperaturas: 20,50 , 100. 150 y $200 " \mathrm{C}$; se calculó la media aritmética de cada temperatura. Especial atención se dedicó a los valores extremos de 20 y $200{ }^{\circ} \mathrm{C}$.

Para conocer la influencia de la edad o almacenamiento durante 10 días se tomaron muestras de una fábrica y se ensayaron. a 20 y $200^{\circ} \mathrm{C}$. cuando tenían la edad de 1 . 3 y 15 días: relacionando el factor con la edad a cada temperatura. 


\section{Valoración del trabajo experimental}

Se aplicó un análisis estadístico para conocer la significación de las diferencias encontradas entre los valores medios calculados para cada temperatura y también para establecer el intervalo real en el cual los valores del factor tenían el $95 \%$ de probabilidades.

Parece que la temperatura elevada, en el intervalo 20 y $200^{\circ} \mathrm{C}$, tienen efectos desfavorables sobre la molturabilidad. El estudio ha demostrado que en las condiciones industriales los factores físicos del clínker varían más ampliamente que la molturabilidad al variar la temperatura.

El resultado de los ensayos con clínker en función del almacenado o edad fue inesperado; se suponía que el tiempo de almacenado tenía una influencia favorable sobre la molturabilidad, pero el factor KvTi revela una tendencia inversa. Se puede explicar por qué el enfriado rápido origina, en el clínker, tensiones; cuando el clínker se almacena las reacciones formativas continúan hacia un estado de equilibrio, las tensiones originadas por los cambios de fases, principalmente las debidas a la fase vítrea "congelada", en consecuencia aparece una estabilización de la masa con un efecto adverso sobre la molturabilidad.

\section{Ensayos en fábrica}

A escala industrial se realizó un ensayo en una fábrica de cemento sobre la base de las conclusiones obtenidas en la investigación de laboratorio, pues si bien éstas indican una disminución de la molturabilidad al elevar la temperaturá, no sugieren que la disminución del factor KvTi pueda ser solamente la causa de una significativa péndida de calidad en el cemento.

El objeto inmediato fue conocer la influencia de la temperatura del clínker sobre el rendimienta del molino. Se realizó en un molino de dos compartimentos $(13,25 \mathrm{~m}$ de largo, $2 ; 40 \mathrm{~m}$ de diámetro interior y 19 r.p.m.).

\section{Procedimiento}

Se molturó clínker, de calidad normal, producido por vía húmeda. Su factor KvTi oscilaba a $20^{\circ} \mathrm{C}$ entre 1,14 y 1,26 ; a $200^{\circ} \mathrm{C}$ : $0,98-1,10$. Se le adicionó 2 a $3 \%$ de yeso y el cemento portland producido era de calidad P-400.

El ensayo se condujo en dos etapas: En la primera, (6 horas) con marcha uniforme del molino, se molturó clínker enfriado. En la segunda etapa el clínker se vertió directamente del horno al molino. Durante el ensayo se vigilaban a intervalos constantes el rendimiento, el tipo de clínker y del cemento; en las muestras tomadas se ensayó la duración del fraguado. Cuando el principio del fraguado descendió, a consecuencia de la temperatura, cada vez más alta del cemento obtenido, se detuvo el ensayo después de 255 minutos. En la segunda etapa se realizaron con el cemento los usuales ensayos técnicos.

\section{Evaluación de los resultados}

El ensayo de fábrica demostró que la buena marcha del molino, en términos de cemento obtenido, depende de la temperatura del clínker; cuando ésta se eleva de $90^{\circ} \mathrm{C} \mathrm{a}, 200^{\circ} \mathrm{C}$, el rendimiento del molino decrece, en una hora, el $25 \%$. En el conjunto de los ensayos la 
temperatura del cemento tendió continuamente a subir; al detener el ensayo, el cemento tenía $160-170^{\circ} \mathrm{C}$ y es de suponer que, si se hubiese continuado, hubiera seguido elevándose.

El alza de la temperatura produce una disminución del tiempo inicial del fraguado atribuible a la deshidratación del yeso.

La continuada subida de la temperatura no causó dificultades en la circulación del aire, pero éste también aumentó su temperatura; el consumo específico de energía eléctrica aumentó a consecuencia de la reducción de la producción del molino.

T A B L A 1

Parámetros de la molienda de clínker caliente

\begin{tabular}{llcc}
\hline & & Clínker frío & Clínker caliente \\
\cline { 2 - 4 } Temperatura del clínker ${ }^{\circ} \mathrm{C}$ & mín. & 75,4 & 167,9 \\
& máx. & 111,1 & 221,3 \\
& media & 91,7 & 204,3 \\
Temperatura del cemento ${ }^{\circ} \mathrm{C}$ & mín. & 103 & 112 \\
& máx. & 132 & 174 \\
Temperatura del aire circulante ${ }^{\circ} \mathrm{C}$ & media & 118 & - \\
& & 47 & 56 \\
Rendimiento del molino $\mathrm{t} / \mathrm{h}$ & & 24,7 & (ascendente) \\
Cosumo específico de energía $\mathrm{kWh} / \mathrm{t}$ & & 28 & 18,2 \\
Ensayos tecnológicos & & & 38 \\
\hline Peso del litro g/dm ${ }^{3}$ & & 1.116 & 1.116 \\
Residuo sobre el tamiz & & 0,6 & 0,8 \\
Blaine $\mathrm{cm}^{2} / \mathrm{g}$ & $0,2 \mathrm{~mm}$ & 7,4 & 7,2 \\
Principio del fraguado & $0,09 \mathrm{~mm}$ & 2.868 & 3.004 \\
Fin del fraguado & & $2 \mathrm{~h} 10 \mathrm{~min}$ & $1 \mathrm{~h} 35 \mathrm{~min}$ \\
\hline
\end{tabular}

\section{CONCLUSIONES}

El conjunto de los ensayos demostró que la reducción del factor de molturabilidad KVTI en el intervalo $20^{\circ}-200^{\circ} \mathrm{C}$ es, a lo sumo, no mayor del $5 \%$ y no es la causa de la disminución, en un $25 \%$, de la eficacia del molino en el ensayo a escala industrial ; evidentemente otras influencias condicionan la molienda del clínker caliente, especialmente el efecto de las cargas electrostáticas engendradas durante la molturación.

Desde el punto del fabricante no es sólo el observado menor rendimiento, sino también la alteración de las propiedades tecnológicas del cemento obtenido producidas por la deshidratación del yeso los efectos más notables producidos por la elevación de la temperatura.

La única medida efectiva para reducir estos efectos adversos es el enfriamiento del molino mediante la pulverización exterior de agua. Las condiciones óptimas para moler clínker de cemento portland se alcanzan cuando se muele clínker reciente y enfriado. 